\title{
Influence of water addition on mechanical properties of thermoplastic starch foils**
}

\author{
Dariusz Chocyk ${ }^{1}$, Bożena Gładyszewska², Anna Ciupak², Tomasz Oniszczuk³, Leszek Mościcki, \\ and Andrzej Rejak \\ ${ }^{1}$ Department of Applied Physics, Lublin University of Technology, Nadbystrzycka 38, 20-618 Lublin, Poland \\ ${ }^{2}$ Department of Physics, University of Life Sciences, Akademicka 13, 20-950 Lublin, Poland \\ ${ }^{3}$ Department of Food Process Engineering, University of Life Sciences, Doświadczalna 44, 20-236 Lublin, Poland
}

Received November 4, 2014; accepted May 12, 2015

\begin{abstract}
A b s t r a c t. The aim of this paper is to study the influence of water on the mechanical properties of thermoplastic starch films. Experimental observations of Young modulus and the breaking force of thermoplastic starch foils with different percentages of polyvinyl alcohol and keratin additives and screw rotation speeds are reported. Thermoplastic starch foils are prepared by the extrusion method with the bowling from potato starch and glycerol as a plasticizer. Young modulus and the breaking force were determined by the random marker method. Measurements of Young modulus and the breaking force of the films were performed after their production and after dosing with water. It was observed that in all cases Young modulus decreases after dosing with water, but the breaking force lied in the same range. Thermoplastic starch foils produced at the screw rotation speed equal to 60 r.p.m. have the best mechanical properties. The highest value of Young modulus and the breaking force were obtained for samples with a $1 \%$ keratin additive.
\end{abstract}

$\mathrm{K}$ e y w o r d s: thermoplastic starch, biodegradable foils, Young modulus, extrusion, mechanical properties

\section{INTRODUCTION}

Environmental care and attempts to solve the problem of waste management are the reason why many researchers produce new packaging materials with mechanical properties comparable to those of conventional plastics. It is estimated that about $44 \%$ of produced plastics, such as packaging foil, gardening items, and disposable items, have short life and quickly become a waste (Raport of EC, 2011). Replacement of plastic materials by biodegradable polymers significantly reduces the volume of waste, especially those with short-term use, or where recycling is difficult to perform or exceeds the cost of production of the new packag-

*Corresponding author e-mail: d.chocyk@pollub.pl

**This work was financed from the budget for science as research project No. NN313 704740 (2011-2014). ing (Avella et al., 2005; Swain et al., 2004; Zhao et al., 2008). Degradation of a material is a complex and timedependent process whose mechanism depends on environmental conditions and additives specially built into the macromolecule of the material from which the decomposition process is started (Dilara and Briassoulis, 2000; Mościcki et al., 2007). In the case of polymers, the process can take place through changes in temperature (thermodegradation), effects of light (photodegradation), ultrasound, biological and chemical agents as well as during mechanical stress and deformation of the material (Chiellini and Solaro, 1996; Dilara et al., 2000).

For many years, polymers have been prepared from a mixture of synthetic and natural polymers that are partially biodegradable. Now completely biodegradable packaging materials are made from plant materials, mainly from starch (Avella et al., 2005; Lu et al., 2009; Mościcki et al., 2007; Swain et al., 2004), proteins, cellulose, and rubber (Phan et al., 2009; Schwach and Avérous, 2004; Zhao et al., 2008).

Starch is formed from carbon dioxide and water in the process of photosynthesis. It is a completely biodegradable semi-crystalline polymer and a supplementary material for most plants (Avella et al., 2005; Lu et al., 2009; Liu et al., 2009). Under the action of high temperature and shear, starch can be converted into a mouldable thermoplastic, a material known as thermoplastic starch (TPS). Therefore, TPS, which is a starting material for the manufacture of products containing natural plasticizers and biodegradable hydrophilic substances (Liu et al., 2009; Lu et al., 2009; Ning et al., 2008; Mościcki et al., 2007; Swain et al., 2004), is degraded in both aerobic and anaerobic conditions

(C) 2015 Institute of Agrophysics, Polish Academy of Sciences 
(Mościcki et al., 2007). Due to its low production cost and easy availability of components, starch-based materials are widely used in food industry (Avella et al., 2005; Lu et al., 2009; Phan et al., 2009; Zhao et al., 2008), agriculture (Lu et al., 2009; Dilara et al., 2000; Ning et al., 2008), and medicine (Araújo et al.; 2004; Azevedo et al., 2003; Marques et al., 2002; Nair and Laurencin, 2007; Rinaudo, 2006). Specific properties of starch, including phase transition during heat treatment, mechanical properties, and microstructure of the material prepared, strongly depend on the conditions and techniques applied for producing such materials (Liu et al., 2009). Additionally, strength properties of starch material are also influenced by the percentage of starch and additives of reinforcing vegetable fibres (Ashori and Nourbakhah, 2008; Georgopoulo et al., 2005; Nourbakhah and Ashori, 2008; Mani and Bhattacharya, 2001; Ratto et al., 1999).

A disadvantage of starch-based plastics is their sensitivity towards water. Variation of the water content of the material as a function of changes in relative humidity leads to (uncontrollable) changes in the mechanical properties. Therefore, in our previous work (Gładyszewska et al., 2013), we focused on dependence of Young modulus and breaking force on soaking time. The aim of this paper is to study the influence of water on the mechanical properties of TPS films. We present the results of stress tests for TPS films produced from potato starch and glycerin with the addition of polyvinyl alcohol and keratin obtained for different screw rotation speeds during production. Measurement of Young modulus and breaking strength were performed using random marker method for dry samples and samples subjected to water.

\section{MATERIAL AND METHODS}

The main component of TPS films was potato starch mixed with glycerol as a plasticizer. Polyvinyl alcohol and keratin were used as additives. Thermoplastic starch was prepared from potato starch 'Superiol' $(73.11 \% \mathrm{w} / \mathrm{w}$ amylopectin and $26.89 \% \mathrm{w} / \mathrm{w}$ amylose) from PPS 'PEPEES' (Łomża, Poland) and glycerol (99.5\% purity) from BIOPETROL MARKETING Denmark, purchased in Brenntag Poland Sp. z o.o in Lublin. Polyvinyl alcohol (mol. wt. 72 000) originated from POCH Gliwice (Poland) and keratin was produced by PROTEINA Label Natural Protein SC in Łódź (Poland). The composition of the raw material samples is given in Table 1.

Thermoplastic starch foils were prepared from starch granulates obtained by the extrusion method with the bowling. The extrusion-cooking process was performed using a modified single screw extrusion-cooker type TS 45 (Polish design) with $\mathrm{L} / \mathrm{D}=18 / 1$ ( $\mathrm{L}$ is the length, and $\mathrm{D}$ the diameter of the screw). The extruder was equipped with an additional cooling section of the barrel. During the extrusion-cooking process, the temperature on each section was
T a b l e 1. Composition of samples

\begin{tabular}{|c|c|c|}
\hline Sample & \multicolumn{2}{|c|}{ Material (\%) } \\
\hline \multirow{3}{*}{ SGA1 } & potato starch & 78 \\
\hline & glycerol & 20 \\
\hline & polyvinyl alcohol & 2 \\
\hline \multirow{3}{*}{ SGA2 } & potato starch & 79 \\
\hline & glycerol & 20 \\
\hline & polyvinyl alcohol & 1 \\
\hline \multirow{3}{*}{ SGA3 } & potato starch & 79.5 \\
\hline & glycerol & 20 \\
\hline & polyvinyl alcohol & 0.5 \\
\hline \multirow{3}{*}{ SGK1 } & potato starch & 78 \\
\hline & glycerol & 20 \\
\hline & keratin & 2 \\
\hline \multirow{3}{*}{ SGK2 } & potato starch & 79 \\
\hline & glycerol & 20 \\
\hline & keratin & 1 \\
\hline \multirow{3}{*}{ SGK3 } & potato starch & 79.5 \\
\hline & glycerol & 20 \\
\hline & keratin & 0.5 \\
\hline
\end{tabular}

$80-120^{\circ} \mathrm{C}$. The temperature was kept by controlling the intensity of cooling fluid flow. The screw rotations ranged from 50 to 80 r.p.m. The rotational speed of the screw was monitored using an electronic tachometer DM-223AR Wireless. The physical parameters of processed materials frequently depend on technological parameters and on the composition of samples. We prepared samples with screw rotation speeds of 50,60, 70, and 80 r.p.m. (rotation per minutes). During the extrusion and film blowing, foil sleeves were obtained with thicknesses in the range of 0.1$0.15 \mathrm{~mm}$ and width of about $1 \mathrm{~m}$. For the measurement of mechanical properties, dumbbell shaped samples were cut. A minimum of several dozen samples were cut from the foil sleeves obtained for each composition and for each screw rotation speed. The samples had a length of $50 \mathrm{~mm}$ and a width of $20 \mathrm{~mm}$ at their tapered part. To study the effect of water on Young modulus and breaking force, measurements were performed before and immediately after dosing $0.5 \mathrm{~cm}^{3}$ of fresh water at a constant temperature of $26.5^{\circ} \mathrm{C}$. A standard pipette was used for dosing the same amount of water to the surface of the sample in each case.

In order to study the structure of TPS foils, a Philips X'Pert PW 3040/60 X-ray diffractometer with the CuKa radiation $(\lambda=1.54056 \AA)$ and with a generator operated at 
$50 \mathrm{kV}$ and $30 \mathrm{~mA}$ was used. A graphite monochromator was used to select the $\mathrm{K} \alpha 1$ radiation. The radiation was detected with a proportional detector. All X-ray diffraction profiles were measured in $\theta-2 \theta$ geometry from 10 to $30^{\circ}$ with the step $0.01^{\circ}$ and counting time $5 \mathrm{~s}$ per data point.

Young modulus and breaking force were measured by the random marker method. This method was described in detail by Gładyszewska (2007). The method is based on analysis of the relative position of markers randomly distributed on the surfaces of tested samples. In this method, we determine changes in the position of markers on the surface of a sample before and after the action of tensile force. The change in the distance between two arbitrarily chosen points before and after deformation is treated as relative elongation of a linear element arranged at any angle to the direction of the force. The general relationship between the relative elongation of the linear element and the strain tensor allows determination of strain tensor components expressed in the direction of the analyzed linear element. To determine all components of the strain tensor, a necessary condition is to know the relative elongation of at least three linear elements not lying on a straight line. The strain tensor obtained is not expressed in the direction of the main axis. The relationship between the strain tensor components expressed in two different reference systems rotated by any angle allows us to find this angle. Knowledge of the angle between reference systems and the strain in the system rotated relative to the main axis, explicitly allows us to calculate the main strain, which is used to calculate Young modulus (Gładyszewska and Chocyk, 2004).

This method allows directing the connection between the sample deformation and stresses in the sample. By applying the random marking method in strength tests, one can neglect boundary conditions, which make the results obtained independent of material strain in the area of critical cross-sections (Gładyszewska, 2006). Force direction is chosen in such a way that the sample is stretched precisely in its plane. The applied markers do not affect sample properties as in many of the existing techniques using periodic patterns to study the displacement fields and the strain fields. In those techniques, the patterns have to be deposited onto the sample directly engraved by the beam on the surface or on an additional layer deposited on the studied surface. Then, it is possible to obtain wrong results by stiffening the surface layer of the tested material due to the line system. In our method, markers not connected to each other and located randomly on the surface of the sample do not introduce any additional stress. Therefore, the natural mechanical properties of the studied material are preserved. The sample is placed in clamping grips. One of the grips is connected to a tensometer with a force measurement range of 0-100 N. The second grip is a moving grip. During the strength test, the sample image generated by a camera equipped with a microscope lens is transmitted to a computer with information of the value of the tensile force corresponding to the given image. The operating resolution of the captured image is $240 \times 320$ pixels. The value of the tensile force and the sample strain are later correlated.

For each case, a minimum of a dozen measurements were performed and the corresponding mean values were calculated. The maximum measurement uncertainty was determined by the logarithmic method and marked in the figures. Additionally, all data were subjected to analysis of variance (ANOVA) using Origin 8.1 BONFERRONI test (2013).

\section{RESULTS AND DISCUSSION}

Generally, in the native starch, one can distinguish two types of crystalline structure and a significant contribution of the amorphous phase. One, the A-type is exhibited for cereal starches. The second one, the B-type is characteristic for amylose-rich starches (Schlemmer et al., 2007). However, in the thermoplastic starches with the glycerol as a plasticizer, there is also a $\mathrm{V}_{\mathrm{h}}$-type structure. The existence of the $\mathrm{V}_{\mathrm{h}}$-type crystalline structure was commonly connected with the interactions established between starch and glycerol (as a plasticizer) during fabrication (Girones et al., 2012; Schlemmer et al., 2007). Examples of $\theta-2 \theta$ X-ray diffraction profiles for sample SGK2 and for sample SGA1 are shown in Figs 1 and 2, respectively. X-ray diffraction measurements were performed a few days after production. For both samples, X-ray profiles revealed a wide peak from the amorphous phase and weak peaks from the small crystalline friction. In all cases, we can distinguish a peak position at approximately $2 \theta=17.0,22.2^{\circ}$ from the B-type structure and peaks at approximately $2 \theta=13.2$, $19.6^{\circ}$ from the $V_{h}$-type crystalline. Peaks from the B-type and $\mathrm{V}_{\mathrm{h}}$-type crystalline structures are indicated in the figures. The degree of crystallinity was estimated according to Hulleman et al. (1999) at about 6\% for all samples. The degree of crystallinity of native starch is about 22\% (Gernat et al., 1990). The B-type crystalline has been attributed to the fast re-crystallization of amylose during cooling after production (Forssel et al., 1997).

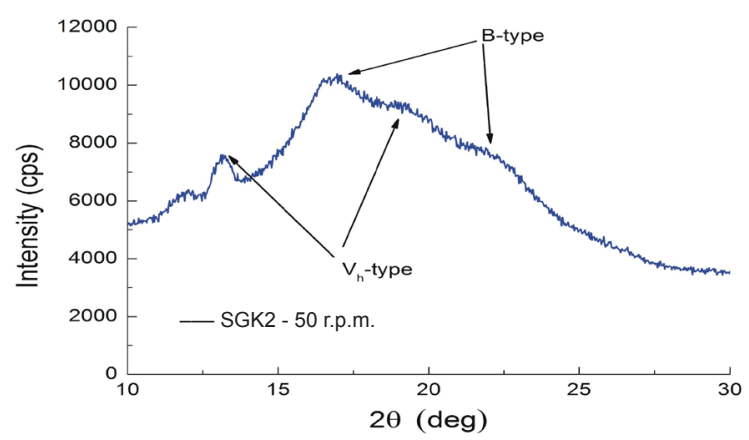

Fig. 1. X-ray diffraction intensity (cps - count per seconds) profiles for a thermoplastic starch sample with $1 \%$ keratin of total weight (SGK2) prepared with screw rotation speeds equal to 50 r.p.m. with an indicated position of peaks originating from the crystalline structure. 


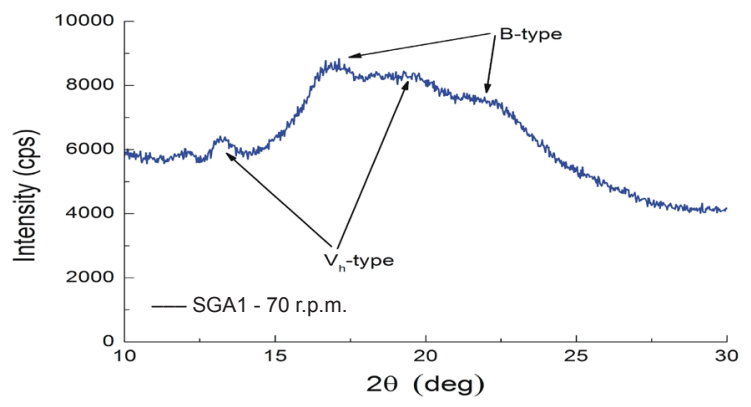

Fig. 2. X-ray diffraction intensity (cps - count per seconds) profiles for thermoplastic starch sample with $2 \%$ the polyvinyl alcohol total weight (SGA1) prepared with screw rotation speeds equal to 70 r.p.m. with an indicated position of peaks originating from the crystalline structure.

Figures 3 and 4 show the breaking force and Young modulus dependences versus rotation speeds of the screw for samples before and after dosing with fresh water. One can observe that values of the breaking force are in the same range before and after dosing with water. In contrast to the breaking force measurement, we can observe significant changes in the value of Young modulus before and after dosing with water for all rotation speeds of the screw. For samples containing keratin, at a rotation speed of 60 and 70 r.p.m., we obtain similar values of Young modulus and breaking force. However, for the samples with the addition of polyvinyl alcohol, we observe a very large increase

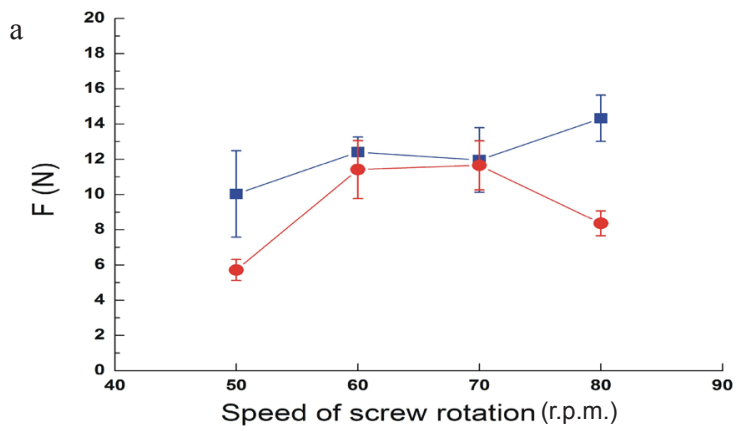

in the value of Young modulus for the speeds of 70 and 80 r.p.m. In contrast to the samples without added water, in all cases we obtain similar dependence on the screw rotation speed after dosing. The maximum values of Young modulus and the breaking force are obtained for the samples produced at 60 r.p.m. One can conclude from these results that the films obtained with the screw rotation speed of 60 r.p.m. during the manufacturing have the best elastic properties. For these screw rotation speeds, the breaking force remains almost the same, but Young modulus is decreased about 2.5 times for the samples with the addition of polyvinyl alcohol. For samples with the addition of keratin, the effect of water is well pronounced, and the maximum effect is produced at 60 r.p.m.

The results of the measurement of breaking force and Young modulus for three different concentrations of keratin and polyvinyl alcohol additives are shown in Figs 5 and 6, respectively. These results also show that the value of Young modulus is significantly reduced by water, but the breaking force is in the same range before and after dosing with water. However, depending on the additive, there is a difference between the behaviour of Young modulus and the breaking force. In the case of polyvinyl alcohol, the lowest values of Young modulus and the breaking force are obtained for $1 \%$, both before and after dosing with water. In contrast to this, samples containing keratin showed the maximum values of both Young modulus and breaking force for the $1 \%$ additive.

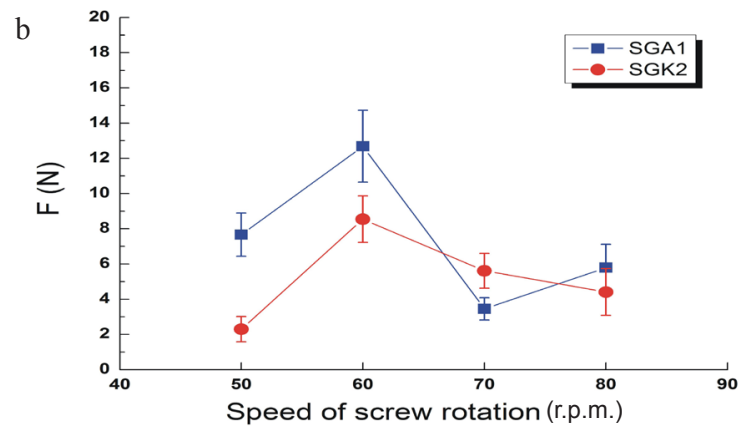

Fig. 3. Dependence of the value of breaking force $\mathrm{F}(\mathrm{N})$ on screw rotation speeds for thermoplastic starch samples with $2 \%$ the polyvinyl alcohol (SGA1) and $1 \%$ keratin (SGK2) of total weight: $\mathrm{a}$ - before, $\mathrm{b}$ - after dosing $0.5 \mathrm{~cm}^{3}$ water.
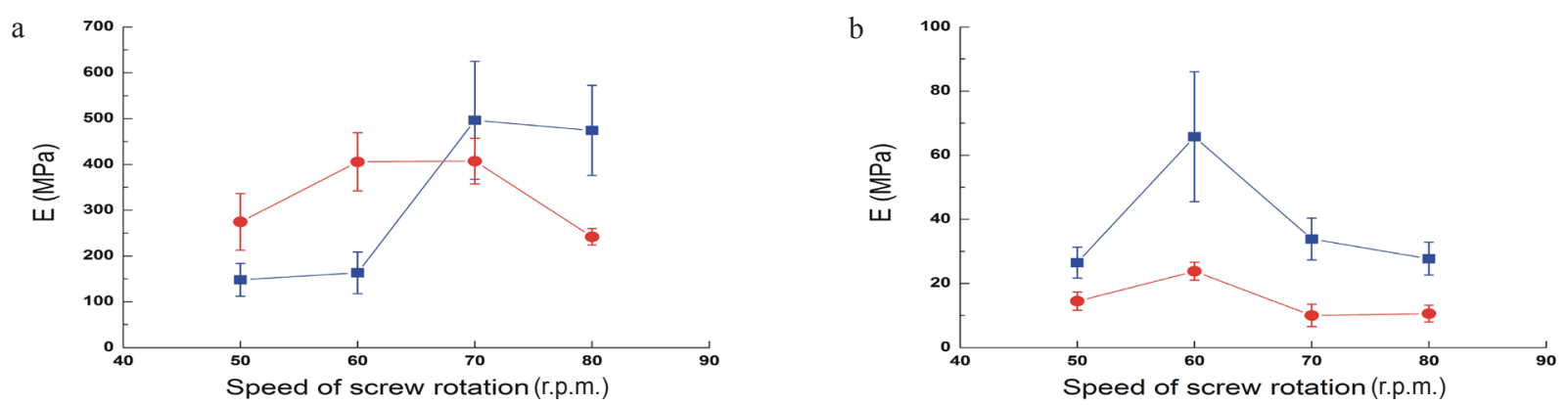

Fig. 4. Dependence of the value of Young modulus E (MPa) on screw rotation speeds for thermoplastic starch samples with $2 \%$ the polyvinyl alcohol (SGA1) and 1\% keratin (SGK2) of total weight: $\mathrm{a}$ - before, $\mathrm{b}$ - after dosing $0.5 \mathrm{~cm}^{3}$ water. Explanations as in Fig. 3. 
a

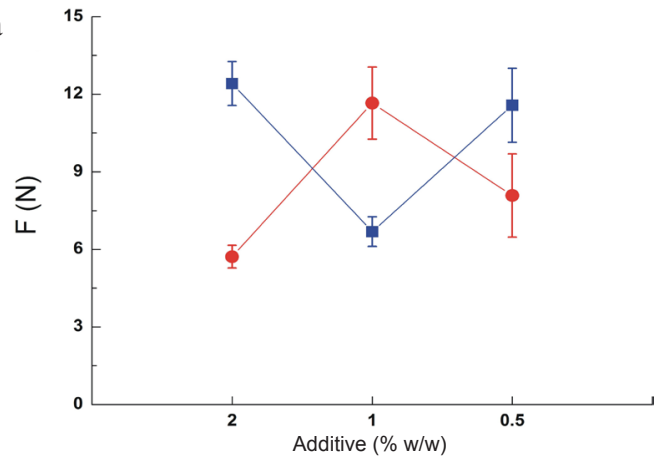

b

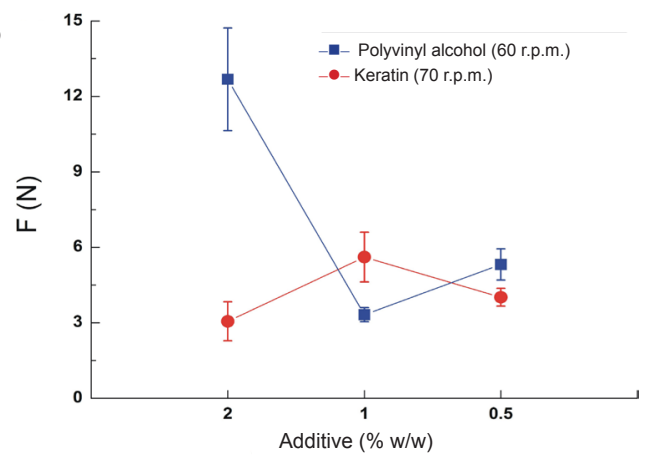

Fig. 5. Dependence of the value of breaking force $\mathrm{F}(\mathrm{N})$ on the total weight percentage of additives (polyvinyl alcohol and keratin) for thermoplastics starch samples obtained at 60 and 70 r.p.m.: a - before, b-after dosing $0.5 \mathrm{~cm}^{3}$ water.

a

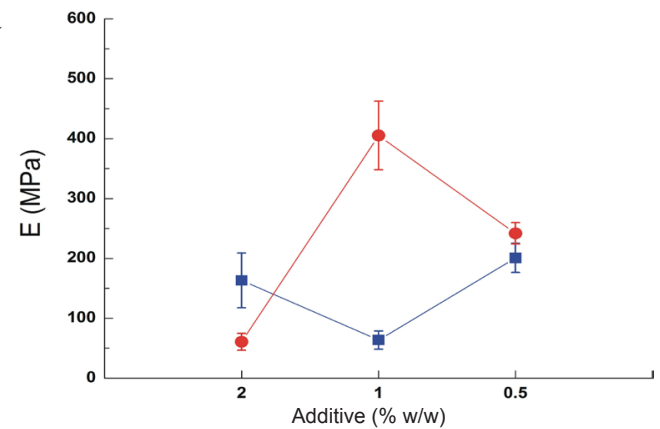

b

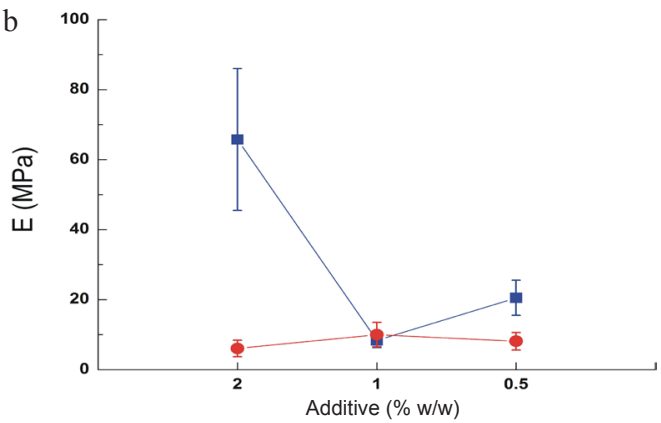

Fig. 6. Dependence of the value of Young modulus E (MPa)on the total weight percentage of additives (polyvinyl alcohol and keratin) for thermoplastic starch samples obtained at 60 and 70 r.p.m.: a - before, b - after dosing $0.5 \mathrm{~cm}^{3}$ water. Explanations as in Fig. 5.

The results presented above show that water has a high impact on the mechanical properties of finished starchbased materials. Air humidity varying the water content of starch-based products can change not only the mechanical properties. At low humidity, there are problems with brittleness, and at high humidity there are problems with softness. Therefore, other plasticizers are frequently used to improve the mechanical properties of starch-based films. For example, plasticizers can increase film flexibility by reducing the internal hydrogen bonding between polymer chains by increasing intermolecular space (Liu et al., 2009). Plasticizers also play an important role in processing. In blown film processing, materials based on starch are required to have high melt strength and extensibility to form good foils. It has been reported that water used as a plasticizer reduces the viscosity of samples during thermal processing (Lai and Kokini, 1990; Thuwall et al., 2006; Willet et al., 1995). Glycerol is used to improve extensibility during the blowing process. Polyvinyl alcohol and keratin is also blended with starch to overcome the naturally bad processibility of raw starch and to eliminate the influence of external factors on its mechanical properties.
Dosing with water is associated with absorption processes. Absorption of water results in a change in the proportion of starch and plasticizer. Consequently, a change in the ratio of starch and plasticizer leads to a reduction in the degree of crystallization, resulting in a decrease in the value of Young modulus. However, changes caused by simple absorption of water can also be a result of the dissolution process of starch. Both of these processes lead to an increase in the plasticizer to starch ratio whereas dissolution of starch decreases crystallinity. An increase in the crystallinity of TPS leads to an increase in the elastic modulus. The role of each process is not obvious, although basically it depends on a number of parameters such as processing history and presence of additives. In summary, water absorption processes result in both dissolution and an increase in the plasticizer and a decrease in crystallinity in samples.

The analysis of variance showed that both Young modulus and the breaking strength in the samples obtained at different screw rotation speeds and different concentrations of keratin and polyvinyl alcohol additives were statistically significant. Also, the post-hoc test $(\alpha=0.05)$ confirmed that the average values of Young modulus and breaking strength were statistically significant. 


\section{CONCLUSIONS}

1. We have found that the degree of crystallinity starch films is about $6 \%$ irrespectively on water addition and rotation speed.

2. The value of Young modulus of as-prepared samples is higher than that of samples dosed with water.

3. The foils obtained at 60 r.p.m. have the best elastic properties of the samples.

4. Dosing with water does not affect the breaking force for all samples.

5. Samples with $1 \%$ of keratin have the highest value of Young modulus and breaking force.

\section{REFERENCES}

Araújo M.A., Cunha A., and Mota M., 2004. Enzymatic degradation of starch-based thermoplastic compounds used in protheses: Identification of the degradation products in solution. Biomaterials, 25, 2687-2693.

Ashori A. and Nourbakhah A., 2008. Acomparative study on mechanical properties and water absorption behavior of fiber-reinforced polypropylene composites prepared by OCC fiber and aspen fiber. Polymer Composities, 29, 574-578.

Avella M., de Vlieger J.J., Errico M.E., Fischer S., Vacca P., and Volpe M.G., 2005. Biodegradable starch/clay nanocomposite films for food packaging applications. Food Chem., 93, 467-474.

Azevedo H.S., Gama F.M., Reis R.L., 2003. In vitro assessment of the enzymatic degradation of several starch based biomaterials. Biomacromolecules, 4, 1703-1712.

Chiellini E. and Solaro R., 1996. Biodegradable polymeric materials. Advanced Materials, 4, 305-313.

Dilara P.A. and Briassoulis D., 2000. Degradation and stabilization of low-density polyethylene films used as greenhouse covering materials. J. Agric. Eng. Res., 76, 309-321.

Forssel P., Hulleman S., Myllärinen P., Moatss G., and Parker R., 1997. Aging of rubbery thermoplastic barley and oat starches. Carbohydr. Polym., 39, 43-51.

Georgopoulos S.Th., Tarantili P.A., Avgerinos E., Andreopoulos A.G., and Koukios E.G., 2005. Thermplastic polymers reinforced with fibrous agricultural residues. Polymer Degradation Stability, 90, 303-312.

Gernat C., Radosta S., Damaschun G., and Schierbaum F., 1990. Supramolecular structure of legume starches revealed by X-ray scattering. Starch, 42, 175-178.

Girones J., Lopez J.P., Mutje P., Carvalho A.J.F., Curvelo A.A.S., and Vilaseca F., 2012. Natural fiber-reinforced thermoplastic starch composites obtained by melt processing. Composities Sci. Technol., 72, 858-863.

Gladyszewska B., 2006. Testing machine for assessing the mechanical properties of biological materials. Technical Sci., 9, 21-31.

Gladyszewska B., 2007. Method for testing selected mechanical properties of thin-film biomaterials (in Polish). Sciences Thesis, University of Life Sciences, Lublin, Poland.

Gladyszewska B. and Chocyk D., 2004. Applying Fourier numerical analysis to determination of tensor elements of the deformations of seed covers. Optica Applicata, 34, 134-143.
Gladyszewska B., Oniszczuk T., Ciupak A., Chocyk D., Mościcki L., Rejak A., and Gladyszewski G., 2013. Effect of sweet water on some mechanical properties of biodegradable thermoplastic starch films (in Polish). Przem. Chem., 92, 1525-1527.

Hulleman S.H.D., Kalisvaart M.G., Janssen F.H.P., Feil H., and Vliegenthart J.F.G., 1999. Origins of B-type crystallinity in glycerol-plasticised, compression-moulded potato starches. Carbohydr. Polym., 39, 351-360.

Lai L.S. and Kokini J.L., 1990. The effect of extrusion operating conditions on the on-line apparent viscosity of $98 \%$ amylopectin (amioca) and 70\% amylose (Hylon 7) corn starches during extrusion. J. Rheol., 8, 1245-1266.

Liu H., Xie F., Yu L., Chen L., and Li L., 2009. Thermal processing of starch-based polymers. Progress olymer Sci., 34, 1348-1368.

Lu D.R., Xiao C.M., and Xu S.J., 2009. Starch-based completely biodegradable polymer materials. Express Polymer Letters, 3, 366-375.

Mani R. and Bhattacharya M., 2001. Properties of injection moduled blends of starch and modified biodegradable polyesters. European Polymer J., 37, 515-526.

Marques A.P., Reis R.L., and Hunt J.A., 2002. The biocompatibility of novel starch-based polymers and composites: In vitro studies. Biomaterials, 23, 1471-1478.

Mościcki L., Janssen L.P.B.M., Mirus M., Oniszczuk T., Rejak A., and Juśko S., 2007. Baro-thermal techniques in processing of thermoplastic starch. Acta Agrophysica, 9, 431-442.

Nair L.S. and Laurencin C.T., 2007. Biodegradable polymers as biomaterials. Progress Polymer Sci., 32, 762-798.

Ning W., Jiugao Y., and Xiaofei M., 2008. Preparation and characterization of compatible thermoplastic dry starch/poly (lactic acid). Polymer Composities, 29, 551-559.

Nourbakhah A. and Ashori A., 2008. Fundamental studies on wood-plastic composities: effects of fiber concentration and mixing temperature on the mechanical properties of poplar/ PP composite. Polymer Composities, 29, 569-573.

Origin 8.1., 2013. User Guide, OriginLab Corporation, Northhampton, USA.

Phan T.D., Debeaufort F., Voilley A., and Luu D., 2009. Biopolymer interaction affect the functional properties of edible films based on agar, cassava starch and arabinoxylan blends. J. Food Eng., 90, 548-558.

Raport of European Commission, 2011. DG ENV, Plastic Waste in the Environment. April 2011, Paris, EU.

Ratto J.A., Stenhouse P.J., Auerbach M., Mitchell J., and Farrell R., 1999. Processing, performance and biodegradability of a thermoplastic aliphatic polyester/starch system. Polymer, 40, 6777-6788.

Rinaudo M., 2006. Characterization and properties of some polysaccharides used as biomaterials. Macromolecular Symposia, 245-246, 549-557.

Scarascia-Mugnozza G., Schettini E., Vox G., Malinconico M., Immirzi B., and Pagliara S., 2006. Mechanical properties decay and morphological behaviour of biodegradable films for agricultural mulching in real scale experiment. Polymer Degradation Stability, 91, 2801-2808. 
Schlemmer D., Oliveira R.A., and Sales M.J.A., 2007. Polystyrene/thermoplastic starch blends with different plasticizers. J. Therm Anal. Calorim., 87(3), 635-658.

Schwach E. and Avérous L., 2004. Starch-based biodegradable blends: Morphology and interface properties. Polymer Int., 53, 2115-2124.

Swain S.N., Biswal S.M., Nanda P.K., and Nayak P.L., 2004. Biodegradable soy-based plastics: opportunities and challenges. J. Polym. Environ., 12, 35-43.
Thuwall M., Boldizar A., and Rigdahl M., 2006. Extrusion processing of high amylose potato starch materials. Carbohyd. Polym., 65, 441-446.

Willet J.L., Jasberg B.K., and Swanson C.L., 1995. Rheology of thermoplastic starch: effects of temperature, moisture content, and additives onmelt viscosity. Polym. Eng. Sci., $35,202-210$.

Zhao R. X., Torley P., and Halley P. J., 2008. Emerging biodegradable materials: Starch- and protein-based bio-nanocomposites. J. Material Sci., 43, 3058-3071. 